\title{
Assessing the Queensland Community Corrections RNI (Risk Needs
} Inventory) ${ }^{*}$

\author{
BROOKE RAE WINTERS \& HENNESSEY HAYES ${ }^{1}$
}

\section{Research on the Use of Prediction in Community Corrections}

Concern over risk management in community corrections is not restricted to criminal justice professionals. It is also a public concern (Roberts 1993:19). More modern correctional practices through the use of predictive instruments seek to provide greater protection and safety to the community. A review of the literature indicates that risk prediction is becoming more scientific in its approach.

Basically, prediction involves assessment of risk factors (Andrews, Bonta \& Hoge 1990:24). These risk factors are currently identified in a number of different instruments utilised in various parts of the world. Those most heavily influencing Australian corrections include risk instruments such as the Wisconsin Assessment of Client Risk Scale, Psychopathology Checklist (PCL), Salient Factor Score (SFS), Minnesota Multiphasic Personality Inventory (MMPI), Statistical Information on Recidivism scale (SIR) and in Queensland, the Level of Supervision Inventory (LSI).

As early as 1977, authors such as Carroll (1977:191) recognised that offenders are dealt with on the basis of their crime and an assessment of the risk they pose to society. In principle, few would argue with Schumacker (1985) who described the goals of supervision as the protection of the community and that, as such, supervision should not singularly emphasise either rehabilitation or punishment. He extended this argument to state that 'the focus should be on the assessment and management of the offender in terms of risks and needs' and that, as such, this investment will result in a higher level of protection for the community (Schumacker 1985:44).

Jones (1991:49), on the other hand, argued that: 'While policy makers have an interest in the rehabilitative or 'treatment' effect of community corrections, they were more vocal in their concern for the public safety risks attached to community-based programs'. He also highlights that although public risk is perceived to be a major consideration, there is no indication of what actual level of public risk is thought to be reasonable for a community-based program to be considered as successful (Jones 1991:51).

* The analyses and interpretations presented here are those of the authors and are not representative of the Queensland Department of Corrective Services.

I Queensland Department of Corrective Services; School of Criminology and Criminal Justice, Griffith University. The authors would like to thank Richard Wortley, Patricia Fox and two anonymous reviewers for their helpful comments on earlier versions of this paper. 
No risk assessment scale can perfectly predict all successes and failures (Serin 1993:22; Hayes \& Geerken 1997). This argument is supported by numerous authors including Hoffman \& Aldeberg (1980:45) who stated that 'no actuarial device can take into account all of the variations in human behaviour that may be associated with the presence or absence of recidivism'. Recidivism, though, has been resistant to highly accurate prediction (Holland et al. 1983:203). It can be argued that the reasons for recidivism are as varied as the range of offenders who actually commit the crimes.

Hayner (1958:76) argued that 'sociologists can improve the technique of parole prediction in a manner to more adequately meet the needs of parole boards ... by developing a more satisfactory theoretical basis and by refining the methods of measurement'. This, in large measure, is what prediction seeks to achieve, a capacity for better informed decision making in case management. The outcome of a risk assessment, according to Clear \& Gallagher (1992:166), is not a true prediction of an offender's behaviour. Rather, it corresponds to a probability statement such that the more 'points' an offender accumulates on a risk scale, the more likely he/she is to 'fail' (i.e. re-offend).

\section{Factors Relevant in Predicting Risk}

Andrews et al (1990:24) proposed that prediction involves assessment of risk factors. Risk factors refer to personal attributes and circumstances that can be assessed and are predicative of future criminal behaviour. These authors were of the view that criminogenic 'needs' constitute a subset of risk factors. Needs are attributes of offenders and their circumstances such that when their personal circumstances change, so too do their chances of recidivist behaviour.

Gendreau (1995:6) proposed that two types of predictors exist. 'Static' predictors (predictors that are fundamental to individuals and cannot be changed) are predictive of recidivism. Examples include ascribed offender characteristics such as age and race, as well as family and criminal histories. On the other hand, 'dynamic' predictors are those factors that reflect offenders' current attitudes, values, beliefs and behaviours. Dynamic predictors may include achieved offender characteristics like attitudes towards crime, social achievement, anti-social behaviour and drug abuse and addiction. ${ }^{2}$

For instruments to be effective, Andrews (1997:3) argued for the need to differentiate between 'minor' and 'major' risk factors and concluded that the best risk instruments measure the presence of several major risk factors. ${ }^{3}$ He noted that a composite measure of minor factors would not maximise predictive accuracy. Motiuk (1993:15), however, was of the view that combined assessment of both risk and need significantly improves the ability to predict who is likely to re-offend and who is not. Hart (1997:5) argued that actuarial data is significantly better as a predictor of recidivism than subjective data. ${ }^{4}$ Carroll et al. (1982) also supported this view and claimed that actuarial predictions are more accurate, equitable and consistent than intuitive judgements. It is not possible, however, that any instrument can be $100 \%$ accurate. As noted by Tallant \& Strachan (1995:207), probation officers, like other professionals, carry out risk assessments within limited time periods. Available time, space and resources do not afford corrections staff an appropriate exploration of a fully comprehensive application of risk factors.

2 'Static' and 'dynamic' predictors (i.e. items) constitute much of the risk needs inventory.

3 'Major' risk factors were those shown to be most predictive of re-offending. 'Minor' risk factors, on the other hand, were least predictive of re-offending.

4 Actuarial data refers to information collected systematically via standardised predication instruments, e.g. the RNI. These are compared with 'subjective' information based on an officer's assessment of an offender. 


\section{Risk Prediction Instruments in Australia}

Australia is a nation that shows diversity in its management of State-based correctional services. In recent years this diversity has become less evident in that individual States have adopted a modified version of the Level of Supervision Inventory (LSI). Currently, the LSI or some modified version thereof is used in five Australian States. Western Australia has been using a version of the LSI and is now creating its own system. The Northern Territory uses a simplistic scale that does not classify risk. At least four States have used an adapted version of the LSI at some stage rather than the LSI itself. Canada currently sells the copyright to use the LSI at substantial cost, making adapted versions far more attractive.

\section{Queensland}

Queensland has utilised the Risk Needs Inventory (RNI, an adapted version of the LSI) in community corrections across the state since 1986. Historically, Queensland has been a leader in achieving the introduction of a risk prediction instrument, but is now being surpassed by other States. The RNI consists of 65 binary coded items which together combine to form the following 12 subscales: criminal history, education/employment, financial, family/marital, accommodation, social interaction, addiction problems, health, driving ${ }^{5}$, attitudes, motivation, extraordinary factors. A detailed explanation of the RNI instrument and its use by Queensland Corrective Services, as well as a description of the use of prediction instruments in other Australian States and territories is given in Winters (1999).

\section{Empirical Research on the RNI}

Earlier studies of the RNI (see, for example, Garvey et al. 1986) did not focus on the instrument's ability to predict re-offending but rather examined whether scores agreed with the experience of assessing officers. Garvey et al (1986) found a $70 \%$ agreement between RNI assessed minimum and maximum risks and assessments made by probation and parole officers with a $60 \%$ agreement on the medium classification category. Duggan et al. (1987) also compared RNI risk categories and levels of risk assigned by probation and parole officers without using the RNI and determined that the RNI was a valid predictor of risk.

Overall there has been limited empirical research into the effectiveness of the RNI as a valid predictor of re-offending. The only study of the predictive validity of the Queensland RNI that has been identified to date was conducted by Cumberland in 1992 for the Consulting Services branch of the Queensland Corrective Services Commission. Cumberland collected data from 281 offenders released into community corrections. This sample included first time male and female offenders who entered the system either through probation or through parole in 1987 (Cumberland 1992:3).

The purpose of Cumberland's study was to assess the validity of the RNI and examine ways in which the RNI could be improved. His findings suggested that the RNI was a statistically valid predictor of the risk of re-offending but was still outperformed by the LSI. This study demonstrated that the RNI predicted re-offending in about $62 \%$ of cases.

5 The driving subscale measures offenders' lawful use of motor vehicles. Individual subscale items include 'currently unlicensed', 'currently suspended [license]', 'currently disqualified [license]', 'poor attitude towards traffic'. 
In summary, Cumberland's (1992:5) study showed that the RNI: (a) is a valid instrument to identify prisoner risk whilst maintaining flexibility to allow for mitigating circumstances; (b) ensures a best-practice approach by combining statistical risk predictors with judgements of practitioners; (c) provides a useful summary of information being considered by decision-makers; (d) adds to the existing processes within the QCSC; and (e) requires minimal training because it has been in use for some time.

Cumberland refuted the appropriateness of the scoring categories and recommended a cut-off score of 6 for recommending release. Offenders scoring 7 or more required written assessment and mitigating circumstances to be allowed release. ${ }^{6} \mathrm{He}$ determined these cut offs by comparing rates of offending and score levels on the RNI. Cumberland only analysed 300 cases of which 281 cases formed the final study from the year 1987 of which he randomly selected $81 \%$ males and 19\% females (Cumberland 1992:3). However, Cumberland's sample size was too small to provide a statistically significant sample. Cumberland's study was further limited by the fact that he only took RNI data from one year. The study described in this paper looks at RNI data collected over eight years. Cumberland's study, on the other hand, has a broader representation of cases across the state whereas this study is limited to the Brisbane area.

In a later study, Cumberland \& Boyle (1997:77) found that the RNI subscales of criminal history, education/employment, financial situation, social interaction and driving predicted both number and severity of recidivism events. The attitudes and motivation subscales indicated shorter-term recidivism only, while the family/marital subscale predicted longerterm recidivism. The health subscale did not correlate significantly with any measure of recidivism but was considered to be a good indicator of need. Accommodation and addiction exhibited only a single significant correlation, suggesting the possible need for psychometric modification of these scales. While Cumberland and Boyle found the RNI to be a valid indicator of predicting re-offending, the instrument was, however, unable to discriminate adequately between recidivism of medium and high risk groups in reoffending.

Translating the subscales of the RNI into individual questions by the Community Corrections Officer when interviewing an offender is by far the instrument's greatest limitation, as not all interviewers ask the same questions. To translate the RNI into specific questions, however, would mean that the RNI would be turned into a several hundred question instrument. By not specifying specific questions, it provides the interviewer with opportunity to elicit the information as he/she sees fit and for what the community correctional officer considers is most appropriate for the client.

Not specifying questions, however, can lend bias to the RNI completion. An informal study conducted by Wilson (1997) identified a number of difficulties with the RNI from data she collected state-wide during case management training. This training involved providing each community correctional officer with a case study of a high-risk offender and requiring staff to complete an RNI on the case. She then compared the final scoring of the instrument and found the range by which Community Correctional Officers in Queensland scored the same study varied from a minimum score of 21 to a maximum score of 54 with a mean RNI score of 37.66 and standard deviation of 5.62. On a local area office basis, Wilson identified that the range of scores was considerable, with a minimum of 28 to a high of 49, mean RNI score of 38.29 and standard deviation of 4.11. Wilson's conclusion was

6 The Risk Needs Inventory (RNI) consists of 65 binary items making up 12 subscales. The possible range for RNI scores is $0-65$ across all subscale items. 
that community correctional officers previously had not been provided with standard guidelines in completing the RNI thus resulting in the scoring disparities. While Wilson's study raises considerable questions about the interrater reliability of the RNI, the study was limited to community correctional officers' assessments of one high-risk offender from a paper description and thus should be interpreted with caution.

Wilson also identified difficulties with the instrument itself, including the sheer length of the RNI (a total 65 items) as well as the instrument's large number of subjective items (e.g. 'high crime' neighbourhood, participation at work/school and use of time) for which it was extremely difficult to provide clear concise written guidelines that would reduce subjective judgement by the community correctional officer completing the RNI. She also was of the view that the division of scores (i.e. 0-9, 10-19 and 20 or more) which assessed classification (i.e. low, medium and high respectively) did not have any valid basis.

In the following analysis we examine the validity of the Risk Needs Inventory currently used by Queensland Department of Corrective Services. We attempt to determine the degree to which the RNI is able to distinguish between 'low-', 'medium-' and 'high-risk' offenders, as well as question the use of 'official overrides' in the classification process. Finally, we summarise the results of our analysis in terms of offender sample characteristics and the predictive power of the RNI.

\section{Data and Methods}

Six hundred offender case files that included a completed RNI were the source of information for this study. ${ }^{7}$ Of the 600 files, offenders on probation, prison probation (i.e. a combination of prison and probation terms) and parole orders were selected, as RNIs are not completed for offenders sentenced to community service or fine options orders. Intensive corrections and home detention orders also were not included because there was an inadequate number to provide a statistically valid sample, and the intensive corrections order was not in existence until the early 1990s. The source of these files was the archives of one of the Community Corrections Area offices within the Brisbane Metropolitan area and includes not only files on offenders who reside within the Brisbane area but also those transferred to Brisbane from other parts of Queensland and from other States in Australia.

Approximately 3,500 files were examined in order to select 600 files that met the criteria for study (i.e. offenders on probation, prison probation, or parole). Files were extracted firstly by order type and then by surname from the different alphabetical groups. Care was taken to ensure that files were selected from both groups on the basis that many migrants, for example, have surnames beginning with ' $S$ ' or ' $W$ '. Selecting through the different alphabet range attempted to reduce bias; however, some systematic bias may still have occurred. The only other factor controlled for besides order type was that of gender to ensure that the study could provide a substantive comparison between male and females. Files on female offenders were consequently over-sampled and resulted in 200 files on females and 400 files on males being selected. Offenders included in this study were both first time and repeat offenders. No sampling bias was used to select specific crime types or number of previous re-offences. 
Finally, data were extracted from files where the community-based order was dated between 13 April 1986 to 17 November 1993 covering nearly an eight-year span. This allowed for the follow-up period to be standardised at 2 and 4 years when examining reoffending. Table 1 provides an overview of the percentage of cases examined over the 8 years selected for file analysis.

\section{Table 1: Number of Files Extracted from 13/4/86 to 17/11/1993}

\begin{tabular}{|l|l|}
\hline \multicolumn{1}{|c|}{ Year of File Extraction } & $\begin{array}{c}\text { Percentage (\%) of Files Extracted } \\
(\mathbf{n}=\mathbf{6 0 0})\end{array}$ \\
\hline 1986 (13 April) & 0.5 \\
\hline 1987 & 14.0 \\
\hline 1988 & 11.0 \\
\hline 1989 & 12.7 \\
\hline 1990 & 20.3 \\
\hline 1991 & 19.8 \\
\hline 1992 & 14.2 \\
\hline 1993 (17 November) & 7.5 \\
\hline
\end{tabular}

As RNI information was recorded manually in Queensland until 1997, data collection had to occur manually. After the eligibility of each file was established according to community-based order and gender type, files were then further examined to see if they were eligible for selection for the study. Only files with a completed (i.e. scored) RNI were selected. Where a community correctional officer had scored the RNI incorrectly, the score was corrected and the file included.

Scores were also cross-referenced with RNI classification to ensure that the RNI score was still consistent with the classifications of high, medium or low. Incorrect scoring was found to occur only in 17 cases. Where incorrect scoring affected the actual classification [ie, low, medium or high] of an offender, these files were excluded.

After a file had been determined as eligible for inclusion in the study, data from the file were recorded on data collection sheets. Information recorded included biographical information, information about the order and type of offence and RNI information.

Individual offenders were identifiable on the data collection sheets only by their $\mathrm{CIS}^{8}$ number. These numbers were removed from the data collection sheets and destroyed to ensure that no individual offender could be identified.

8 CIS is the Correctional Information System currently used by Queensland Corrections to manage offender caseloads. This is a computerised system that includes information regarding an offender's criminal history, personal details and supervision level (Queensland Corrections 1996). 
In addition to the information contained in the RNI, we obtained additional demographic information for each offender in the study using the CIS. Our purpose here was to determine to what degree, if any, variables such as gender and age accounted for an offender's predicted risk of re-offending, as well as determined community supervision level. We should note, however, that while age and gender have been consistently shown to be associated with rates of offending and re-offending, the proposed use of such variables as indicators of potential re-offending raises serious ethical questions (Hayes \& Geerken 1997).

\section{Results}

While a descriptive analysis of the study sample was undertaken and has been presented elsewhere (see Winters 1999), this paper focuses on the results of the RNI analyses. Below, we look at the study sample data in terms of RNI risk classification, offender and offence characteristics, recidivism and prediction.

\section{RNI Classifications and Offender/Offence Characteristics}

Table 2 provides an overview of the classification of risk of the entire sample showing over half the sample to have been classified as a low risk of re-offending and less than 10 percent as classified as a high risk of re-offending.

Table 2: RNI Classification of Original Offence

\begin{tabular}{|l|r|}
\hline \multicolumn{1}{|c|}{$\begin{array}{c}\text { RNI Classification of } \\
\text { Original Offence }\end{array}$} & \multicolumn{1}{c|}{$\begin{array}{c}\text { Total }(\mathbf{n}=\mathbf{6 0 0 )} \\
\text { (\% of total sample) }\end{array}$} \\
\hline Low (score 0 to 9) & $339(56.5 \%)$ \\
\hline Medium (score 10 to 19) & $209(34.8 \%)$ \\
\hline High (score 20 and more) & $52(8.7 \%)$ \\
\hline
\end{tabular}

A statistically significant association was identified between RNI classification and the original type of offence $(\chi 2=26.4, \mathrm{df}=12, \mathrm{p}<.01)$. The association showed that the more serious the offence, the greater was the RNI risk classification. This was to be expected, given that more serious offences are more likely to attract custodial sentences. Those who committed more serious offenders are almost 'predisposed' to being scored higher, particularly in the subscale of criminal history. Table 3 demonstrates this association. 
Table 3: RNI Classification and Original Offence Type

\begin{tabular}{|l|r|r|r|r|r|r|r|}
\hline Order Type & \multicolumn{2}{|l|}{ Nature of Offence } \\
\hline & $\begin{array}{l}\text { Homicide } \\
\text { etc. } \\
(\mathrm{n}=12)\end{array}$ & $\begin{array}{l}\text { Assault } / \\
\text { Sex. Assault } \\
(\mathrm{n}=89)\end{array}$ & $\begin{array}{l}\text { Robbery } \\
\text { Extor- } \\
\text { tion } \\
(\mathrm{n}=33)\end{array}$ & $\begin{array}{l}\text { Theft } \\
\text { B\&E } \\
(\mathrm{n}=269)\end{array}$ & $\begin{array}{l}\text { Property } \\
(\mathrm{n}=21)\end{array}$ & $\begin{array}{l}\text { Traffic } \\
(\mathrm{n}=34)\end{array}$ & $\begin{array}{l}\text { Other } \\
(\mathrm{n}=142)\end{array}$ \\
\hline Low & $33.3 \%$ & $47.2 \%$ & $57.6 \%$ & $61.7 \%$ & $47.6 \%$ & $55.9 \%$ & $55.6 \%$ \\
\hline Medium & $41.7 \%$ & $37.1 \%$ & $21.2 \%$ & $32.7 \%$ & $42.9 \%$ & $38.2 \%$ & $38.9 \%$ \\
\hline High & $25.0 \%$ & $15.7 \%$ & $2.2 \%$ & $5.6 \%$ & $9.5 \%$ & $5.9 \%$ & $6.3 \%$ \\
\hline
\end{tabular}

$\left(\chi^{2}=26.4, \mathrm{df}=12, \mathrm{p}<.01\right)$

Table 4 shows the association between RNI classification and original order type $(\chi 2=38.8, \mathrm{df}=4, \mathrm{p}<.01$ ). The risk classification for those on probation was found to be lower than those on parole and prison probation orders. Again, the argument applies that the more violent offences attract custodial sentences and therefore may predispose the individual to gaining a higher score. Offenders on parole also have greater similarity to those on prison probation orders than those offenders serving probation orders only. Both parolees and prison probationers serve a term in custody before being released to community supervision. This similarity likely explains the more similar risk classifications of parole and prison probations as compared to probation generally.

\section{Table 4: RNI Classification and Original Order Type}

\begin{tabular}{|l|r|r|r|}
\hline Order Type & $\begin{array}{c}\text { Probation } \\
\mathbf{n = 3 8 1}\end{array}$ & $\begin{array}{c}\text { Prison Probation } \\
\mathbf{n = 4 0}\end{array}$ & $\begin{array}{c}\text { Parole } \\
\mathbf{n}=\mathbf{1 7 9}\end{array}$ \\
\hline Low & $64.6 \%$ & $32.5 \%$ & $44.7 \%$ \\
\hline Medium & $29.9 \%$ & $42.5 \%$ & $43.6 \%$ \\
\hline High & $5.5 \%$ & $25.0 \%$ & $11.7 \%$ \\
\hline
\end{tabular}

$\left(\chi^{2}=38.8, \mathrm{df}=4, \mathrm{p}<.01\right)$

There is an association between length of offence and RNI classification $(\chi 2=25.4$, df $=12, \mathrm{p}<.05$ ) which indicates that offenders classified as low and medium received slightly shorter sentences than those classified as high. Nearly $50 \%$ of those classified high were sentenced to more than 2 years. See Table 5 . 
Table 5: Length of Original Sentence and RNI Classification

\begin{tabular}{|l|r|r|r|}
\hline \multicolumn{1}{|c|}{ Length of Original Sentence } & $\begin{array}{c}\text { Low } \\
\mathbf{n}=\mathbf{3 3 9}\end{array}$ & $\begin{array}{c}\text { Medium } \\
\mathbf{n}=\mathbf{2 0 9}\end{array}$ & $\begin{array}{c}\text { High } \\
\mathbf{n}=\mathbf{5 2}\end{array}$ \\
\hline $0-1$ year & $42.5 \%$ & $30.1 \%$ & $23.1 \%$ \\
\hline 1 year +1 day to 2 years & $38.9 \%$ & $43.1 \%$ & $36.5 \%$ \\
\hline 2 years +1 day to 3 years & $13.6 \%$ & $21.1 \%$ & $28.8 \%$ \\
\hline 3 years +1 day to 4 years & $2.4 \%$ & $1.9 \%$ & $5.8 \%$ \\
\hline 4 years +1 day to 5 years & $1.5 \%$ & $2.4 \%$ & $5.8 \%$ \\
\hline 5 years +1 day to 10 years & $.9 \%$ & $1.4 \%$ & $0.0 \%$ \\
\hline 10 years + 1 day and & $.3 \%$ & $0.0 \%$ & $0.0 \%$ \\
\hline
\end{tabular}

$$
(\chi 2=25.4, \mathrm{df}=12, \mathrm{p}<.05)
$$

Table 6 demonstrates the association between RNI risk classification level and the violence classification of the original offence $\left(\chi^{2}=27.0, \mathrm{df}=2, \mathrm{p}<.01\right)$. Again this result was expected given the previous argument that more violent offences may predispose the offender to attracting a higher score. While statistically significant, this result serves more to reinforce that the instrument is able to differentiate, to some extent, between the severity of an offence.

\section{Table 6: RNI Classification and Violence Classification of Offence}

\begin{tabular}{|l|r|r|}
\hline Order Type & \multicolumn{1}{|c|}{ Violent Offence } & Non-Violent Offence \\
\hline Low & $43.7 \%$ & $59.7 \%$ \\
\hline Medium & $36.1 \%$ & $34.5 \%$ \\
\hline High & $20.2 \%$ & $5.8 \%$ \\
\hline
\end{tabular}

$\left(\chi^{2}=27.0, \mathrm{df}=2, \mathrm{p}<.01\right)$ 


\section{Recidivism $^{9}$}

The rate of re-offending within 1 to 4 years is described in Table 7. As shown, 131 of the total 198 who re-offended did so within a 2-year period. Re-offending reduced considerably after the second year, however.

Table 7: Rate of Re-offence 1 to 4 years

\begin{tabular}{|l|r|r|}
\hline $\begin{array}{c}\text { Time when re-offended after } \\
\text { original order }\end{array}$ & $\begin{array}{c}\text { Percentage who re-offended } \\
(\mathbf{n}=\mathbf{1 9 8})\end{array}$ & $\begin{array}{c}\text { Percentage who re-offended as } \\
\text { percentage of total sample of } 600 \\
\text { cases }\end{array}$ \\
\hline 0 to 1 year & $34.3 \%$ & $11.3 \%$ \\
\hline 1 year +1 day to 2 years & $31.8 \%$ & $10.5 \%$ \\
\hline $\begin{array}{l}2 \text { years }+1 \text { day to } 3 \\
\text { years }\end{array}$ & $21.2 \%$ & $7.0 \%$ \\
\hline $\begin{array}{l}3 \text { years }+1 \text { day to } 4 \\
\text { years }\end{array}$ & $12.6 \%$ & \\
\hline
\end{tabular}

Of those who re-offended, there appears to be an association with age $(\chi 2=12.5, \mathrm{df}=$ $4, p<.05)$. Table 8 shows that re-offending in the sample peaked between the ages of 31 to 40 years and then began to decline. This finding is consistent with what is reported in the literature regarding the relationship between age and crime, or what is often characterised as 'maturing out of crime' (Blumstein et al. 1986:23).

\section{Table 8: Age and Percentages of Re-offending}

\begin{tabular}{|c|c|c|c|c|c|}
\hline $\begin{array}{c}\text { Offending } \\
\text { within Four } \\
\text { Years }\end{array}$ & $\begin{array}{c}20 \text { years \& } \\
\text { under } \\
n=1\end{array}$ & $\begin{array}{c}21 \text { to } 30 \text { years } \\
\text { old } \\
n=259\end{array}$ & $\begin{array}{c}31 \text { to } 40 \text { years } \\
\text { old } \\
n=192\end{array}$ & $\begin{array}{c}41 \text { to } 50 \text { years } \\
\text { old } \\
n=95\end{array}$ & $\begin{array}{l}51 \text { years old \& over } \\
\qquad n=53\end{array}$ \\
\hline No new offence & $100.0 \%$ & $64.5 \%$ & $63.0 \%$ & $70.5 \%$ & $86.8 \%$ \\
\hline New offence & $0.0 \%$ & $35.5 \%$ & $37.0 \%$ & $29.5 \%$ & $13.2 \%$ \\
\hline
\end{tabular}

$$
\left(\chi^{2}=12.5, \mathrm{df}=4, \mathrm{p}<.05\right)
$$

9 A methodological weakness associated with these analyses should be noted. The over-sampling of female offenders may have biased the recidivism analyses. While weighting the sample along gender would have addressed this problem, we forewent this strategy as our results were meant to address the predictive potential of the RNI rather than be generalised to any active offender populations. 
Approximately $39 \%$ of men re-offended compared to only $22 \%$ of women. There appears to be an association between gender and rates of re-offending, suggesting that men are more likely to re-offend than women $(\chi 2=16.4, \mathrm{df}=1, \mathrm{p}<0.01$; refer to Table 9).

Table 9: Re-offending and Gender

\begin{tabular}{|l|r|r|r|}
\hline $\begin{array}{c}\text { Offending within Four } \\
\text { Years }\end{array}$ & $\begin{array}{c}\text { Females } \\
\mathbf{n}=\mathbf{2 0 0}(\mathbf{3 3 . 3} \%) \\
(\% \text { of Females) }\end{array}$ & $\begin{array}{c}\text { Males } \\
\mathbf{n}=\mathbf{4 0 0}(\mathbf{6 6 . 7} \%) \\
(\% \text { of Males) }\end{array}$ & $\begin{array}{c}\text { Total } \\
\mathbf{n}=\mathbf{6 0 0}(\mathbf{1 0 0} \%) \\
(\% \text { of total sample) }\end{array}$ \\
\hline No new offence & $156(78.0 \%)$ & $246(61.5 \%)$ & $402(67.0 \%)$ \\
\hline New offence & $44(22.0 \%)$ & $154(38.5 \%)$ & $198(33.0 \%)$ \\
\hline
\end{tabular}

$\left(\chi^{2}=16.4, \mathrm{df}=1, \mathrm{p}<0.01\right)$

There appears to be an association with re-offending and marital status $(\chi 2=19.1, \mathrm{df}=$ $5, \mathrm{p}<.01$; refer to Table 10 ) suggesting that those married were less likely to re-offend but those in de facto relationships were highly likely to re-offend. Again, this finding is consistent with research in deterrence that suggests criminal justice responses are less effective for those offenders who are detached from conventional social institutions (see, for example, Sherman \& Smith 1992).

\section{Table 10: Comparison of Re-offending and Marital Status}

\begin{tabular}{|l|r|r|r|r|r|r|}
\hline $\begin{array}{c}\text { Offended } \\
\text { with four } \\
\text { years }\end{array}$ & $\begin{array}{c}\text { Married } \\
\mathbf{n}=\mathbf{6 8}\end{array}$ & $\begin{array}{c}\text { Divorced } \\
\mathbf{n}=\mathbf{4 0}\end{array}$ & $\begin{array}{c}\text { Widowed } \\
\mathbf{n}=\mathbf{5}\end{array}$ & $\begin{array}{c}\text { Single } \\
\mathbf{n}=\mathbf{3 8 2}\end{array}$ & $\begin{array}{c}\text { De facto } \\
\mathbf{n}=\mathbf{6 6}\end{array}$ & $\begin{array}{c}\text { Separated } \\
\mathbf{n}=\mathbf{3 9}\end{array}$ \\
\hline $\begin{array}{l}\text { No new } \\
\text { offence }\end{array}$ & $83.8 \%$ & $82.5 \%$ & $60.0 \%$ & $63.4 \%$ & $57.6 \%$ & $74.4 \%$ \\
\hline New offence & $16.2 \%$ & $17.5 \%$ & $40.0 \%$ & $36.6 \%$ & $42.4 \%$ & $25.6 \%$ \\
\hline
\end{tabular}

$$
\left(\chi^{2}=19.1, \mathrm{df}=5, \mathrm{p}<.01\right)
$$

Table 11 shows the type of new offences committed. Of the third of offenders who reoffended, most $(17.4 \%)$ were involved in property or traffic offences. 


\section{Table 11: Type of Re-offence Committed within Four Years}

\begin{tabular}{|l|r|}
\hline \multicolumn{1}{|c|}{ Type of Re-Offence } & Percentage (n = 198) \\
\hline No new offence & $(402) 67.0 \%$ \\
\hline Homicide etc. & $(0) 0.0 \%$ \\
\hline Assault / Sexual Assault & (19) $3.2 \%$ \\
\hline Robbery/ Extortion & (5) $0.8 \%$ \\
\hline Theft, Break and Enter & (61) $10.2 \%$ \\
\hline Property & (3) $0.5 \%$ \\
\hline Traffic & (43) $7.2 \%$ \\
\hline Other & (67) $11.2 \%$ \\
\hline
\end{tabular}

Table 12 demonstrates the association found between re-offending and the original order to which a person was sentenced $\left(\chi_{2}=12.2, \mathrm{df}=2, \mathrm{p}<.01\right)$. Of particular interest is the high number of people on prison probation orders who re-offended, suggesting that a combination of orders is perhaps ineffective or that prison terms may be more criminogenic than other orders. There was no relationship between age and the type of order imposed on those who had re-offended.

Table 12: Comparison of Re-offending and Order Type

\begin{tabular}{|l|r|r|r|}
\hline $\begin{array}{c}\text { Offended with } \\
\text { four years }\end{array}$ & $\begin{array}{c}\text { Probation } \\
\mathbf{n}=\mathbf{3 8 1}\end{array}$ & $\begin{array}{c}\text { Prison Probation } \\
\mathbf{n}=\mathbf{4 0}\end{array}$ & $\begin{array}{c}\text { Parole } \\
\mathbf{n}=\mathbf{1 7 9}\end{array}$ \\
\hline No new offence & $69.8 \%$ & $42.5 \%$ & $66.5 \%$ \\
\hline New offence & $30.2 \%$ & $57.5 \%$ & $33.5 \%$ \\
\hline
\end{tabular}

$(\chi 2=12.2, \mathrm{df}=2, \mathrm{p}<.01)$

When comparing the violence classification of the original offence against those who had not re-offended with those who had, again, no association was identified. Of the total sample, of those who were identified as having committed a violent original offence, $30.3 \%$ re-offended. This is compared to non-violent offences, where $33.7 \%$ re-offended, showing little difference. 
Table 13 shows the comparison of offenders classified as low, medium and high on the Queensland RNI by re-offence status. Here there appears to be an association $(\chi 2=59.1$, $\mathrm{df}=2, \mathrm{p}<.01$ ) such that those classified as a low risk of re-offending did in fact re-offend at a lower rate than the mediums and highs. There is little differentiation, however, between re-offending rates for those classified as medium and high suggesting perhaps that the cutoff points on the RNI may be inaccurate.

Table 13: Queensland RNI Classification and Re-offending

\begin{tabular}{|l|r|r|r|}
\hline & $\begin{array}{c}\text { Low (0-9) } \\
\mathbf{n = 3 3 9}\end{array}$ & $\begin{array}{c}\text { Medium (10-19) } \\
\mathbf{n}=\mathbf{2 0 9}\end{array}$ & $\begin{array}{c}\text { High (20+) } \\
\mathbf{n = 5 2}\end{array}$ \\
\hline No new offence & $\mathbf{7 9 . 9 \%}$ & $49.8 \%$ & $51.9 \%$ \\
\hline Re-offended & $\mathbf{2 0 . 1 \%}$ & $50.2 \%$ & $48.1 \%$ \\
\hline
\end{tabular}

$$
\left(\chi^{2}=59.1, \mathrm{df}=2, \mathrm{p}<.01\right)
$$

\section{Predicting Re-offending}

Validity is an indication of the extent to which measurement corresponds with the concept being measured (Tripodi et al, 1969:86). In this view, the RNI may be considered a valid indicator of recidivism risk (see Table 13). Approximately $20 \%$ of those classified as a 'low' risk did, in fact, re-offend, $50.2 \%$ of those classified as 'medium' re-offended and $48.1 \%$ of those classified as a 'high' re-offended. In addition, of those who re-offended, (n $=198$ ) $30.3 \%$ were returned to custody, with 'highs' being sentenced more often to custody $(52 \%)$ than those previously classified as having a low risk of re-offending (19.1\%).

While the statistical association between RNI classification and re-offence is significant $(\chi 2=59.1, \mathrm{df}=2, \mathrm{p}<.01)$, concerns exist as to the actual percentage differentiation across the 3 classification levels. Approximately $20 \%$ of lows do re-offend, and this percentage seems rather high. As discussed previously, the decision concerning what percentage would be considered to be acceptable for a 'low' rating is an arbitrary one. There is also little differentiation between those classified as medium $(50.2 \%)$ or high $(48.1 \%)$ in terms of reoffending, and it is expected that an effective instrument would provide greater differentiation.

Looking at sections of the RNI independently, just under half of the subscales were successful in predicting re-offending (see Table 14). Using stepwise multiple regression, RNI subscales were examined to determine relative predictive utility. Criminal history, social interaction, driving, health, addiction problems and attitudes towards supervision were significant predictors of re-offending. With the exception of attitudes towards supervision, these subscales possess the largest reliability coefficients. 
Table 14: Re-offending Regressed on RNI Classification Scores with Associated Cronbach's Alpha Coefficients

\begin{tabular}{|l|l|l|l|}
\hline \multicolumn{1}{|c|}{ RNI Subscale } & \multicolumn{1}{c|}{ Beta } & \multicolumn{1}{c|}{$\mathbf{t}$} & \multicolumn{1}{c|}{ Cronbach's Alpha } \\
\hline Criminal History & .174490 & $3.777^{* *}$ & .7949 \\
\hline Education and Employment & .082750 & 1.712 & .5872 \\
\hline Finance & .035727 & .810 & .2570 \\
\hline Family and Marital & .010042 & .229 & .3765 \\
\hline Accommodation & .051279 & 1.208 & .3311 \\
\hline Social Interaction & .120264 & $2.487^{*}$ & .6629 \\
\hline Addiction Problems & .050538 & 1.103 & .6954 \\
\hline Health &. .118182 & $-2.756 * *$ & .4996 \\
\hline Driving & .106288 & $2.671^{* *}$ & .4807 \\
\hline Attitude Towards Supervision & -.083854 & $-1.968 *$ & .2609 \\
\hline Motivation & .009459 & .226 & $\begin{array}{l}\text { not possible to calculate }(1 \text { item } \\
\text { only) }\end{array}$ \\
\hline Extra-ordinary factors & .049890 & 1.282 & .5268 \\
\hline
\end{tabular}

* $\mathrm{p}<0.05$

** $\mathrm{p}<0.01$

$\mathrm{R}^{2}=.133$

Overall, the scale accounts for an unimpressive $13 \%$ of the variation in re-offending which is comparable to Cumberland's \& Boyle's 1997 study. What differs, however, are the subscales shown to be predictive of re-offending. Cumberland \& Boyle found the education/employment and finance subscales predictive of recidivism, yet neither of these subscales was predictive in this study. We do note, however, that both these subscales rely substantially on the honesty of the offender and are difficult to be verified through other external sources. 
Two of the RNI subscales that were shown to be predictive of re-offending were inversely associated with recidivism. The first was 'health' such that the more health problems an offender experiences, the less likely he/she was to re-offend. Here, poor health likely limits an offender's opportunities to offend. 'Attitude toward supervision' also was inversely associated with re-offending such that the more non-compliant an offender was considered to be, the less likelihood he or she was of re-offending $(B=-0.083854, p<.05)$. This finding is rather counter-intuitive. Attitude towards supervision is one of the dynamic factors in the RNI and scored according to the individual subjective judgement of a community correctional officer. Yet it is not a factor that can be substantiated from external sources.

\section{Summary}

This study has examined the predictive validity of the Queensland Risk Needs Inventory. While the RNI is statistically valid (see Table 14), it could be substantially improved. Only five of the subscales of the RNI were found to be effective predictors of offending behaviour. The RNI differentiated between the rate of re-offending for those originally classified as low risk but was not effective in separating medium and high risk. Overall it predicted re-offending in 33\% of cases across all classifications of low, medium and high. The RNI did not achieve Cumberland's (1992) figure of predicting re-offending in $62 \%$ of all cases. The best the RNI achieved was to predict $20.1 \%$ re-offending for low classified offenders, $50.2 \%$ re-offending for medium classified offenders and $48.1 \%$ for high-risk classified offenders.

Community Corrections in Queensland currently supervises over 23,000 offenders every year on community-based orders (QCSC Annual Report 1996/97). Just over 8,000 of those are assessed with the RNI. The classification system of the RNI forms the basis for the management and surveillance of those 8,000 offenders and determines the allocation of public resources. The RNI is also used by community correctional boards when making decisions about the release of prisoners back into the community. It is surprising, therefore, that research into the RNI has been extremely limited, with only one other formal study conducted by Cumberland in 1992 which examined 281 files extracted from a one-year period for a follow-up of four years. Our research, on the other hand, has examined 600 files extracted from an 8-year period with a follow-up of 4 years and has become the most extensive study of its kind on the Queensland RNI. The findings of this research should raise questions about the future use of the RNI by the Queensland Department of Corrective Services. Community Corrections boards also need to consider how much weight to give to RNI classifications when determining the release of prisoners back into the community. In light of considerations by Queensland Department of Corrective Services to adopt the LSI-OR, further research is needed to evaluate this instrument before system-wide adoption.

It must be highlighted that there are potential problems with transporting any instrument from one country to another, in this case from Canada to Australia. It is necessary to question the cultural appropriateness of the RNI in assessing the risks and needs of indigenous offenders and the RNI's application to other offenders of varying cultural, economic, political and social backgrounds. Validity of instruments also can be lost when random changes are made, as occurred in the 1980s when staff from the Queensland Probation and Parole Service made adaptations to the LSI and renamed it the RNI. Government officials should be wary of introducing instruments from other countries and making adjustments without first validating the instruments by independent research. 
Most lacking when conducting the current research was the identification of benchmarks for re-offending. For example, what does 'low risk of re-offending' mean? Until benchmarks are established, the concept of low, medium and high risk remains a nebulous one. Benchmarking of risk levels would certainly assist community corrections boards to make more informed decisions.

Currently, an assumption is made that the risk of re-offending is the same for offenders in jail and in the community serving a community-based order. However, some factors on the RNI have no relevance in a custodial environment (e.g. change of address). As a result, the RNI is adjusted in an ad hoc manner by community corrections officers. Further research needs to examine the effects of ad hoc adjustments and, moreover, the effects of incarceration on risk of re-offending.

Another issue arising is that the RNI is only used on reception of an offender to a communitybased order and is not used again unless the person re-offends and is sentenced to a new order. This provides no capacity for a community correctional officer to judge how changes in the dynamic indicators of an offender's circumstances may lead to criminal behaviour. Alternatively, consideration needs to be given to the inclusion of static indicators such as age, gender, marital status and possibly ethnic background to improve the RNI's predictive capacity. The results of this study suggest that these indicators may be associated with re-offending (see, for example, Tables 8-10). Failure to include the variable of gender, for example, could result in the overclassification of female offenders, as males possess the greater likelihood of re-offending.

Additional research needs to be conducted on sex offenders regarding their rate of recidivism. This issue was highlighted by Cumberland (1992). The RNI tends to rate sex offenders at a lower level of risk than other types of offenders for no apparent reason. Consideration may need to be given to incorporating a weighting system into the RNI that addresses recidivism rates for specific crime types. Also noted in this study was the substantially higher rate of re-offence by offenders on prison probation orders than other order types. The RNI perhaps needs to include a weighting for order type as well.

Finally, the reliability of data available on the Correctional Information System may need to be questioned. The process of transferring raw data to a computer may diminish the accuracy of the electronic data to a certain degree.

Researchers and correctional administrators should be reminded that assessment tools like the RNI are predictors of risk and should not be regarded as completely or even routinely accurate. However, as tools they are useful guides and, in some instances, can be made to be more effective in case management. As Trotter (1995) has noted, prediction instruments are more useful than professional or clinical judgement alone.

\section{REFERENCES}

Andrews, DA (1997) 'Criminal Recidivism is Predictable and can be Influenced: An Update,' Department of Psychology, Carleton University, Canada.

Andrews, DA \& Bonta, J (1995) 'The Level of Service Inventory - Ontario Revision', Working paper for the Ministry of the Solicitor-General and Correctional Services, Ontario.

Andrews, DA, Bonta, J, \& Hoge, RD (1990) 'Classification for Effective Rehabilitation Rediscovering Psychology', Criminal Justice and Behaviour, vol 17, pp 19-52.

Blumstein, A, Cohen, J, Roth, J \& Visher, C (1986) Criminal Careers and 'Career Criminals', vol 1, National Academy Press, Washington D.C. 
Carroll, J (1977) 'Judgements of Recidivism Risk', Law and Human Behaviour, vol 1, no 2, pp 191-198.

Carroll, JS, Wiener, RL, Coates, D, Galegher, J \& Alibrrio, J (1982) 'Evaluation, Diagnosis and Prediction in Parole Decision Making', Law and Society Review, vol 17, no 1, pp 199-228.

Clear TR \& Gallagher KW (1992) 'Screening Devices in Probation and Parole: Management Problems' in Ellsworth, $\mathrm{T}$ (ed) Contemporary Community Corrections, Waveland Press Inc.

Cumberland, A (1992) 'The Validity of the Risk Needs Inventory', Consulting Services, Queensland Corrective Services Commission.

Cumberland, A \& Boyle, GJ (1997) 'Psychometric Prediction of Recidivism: Utility of the Risk Needs Inventory', The Australian and New Zealand Journal of Criminology, vol 30, no 1, pp 72-86.

Duggan, CM, Evans, RJ \& Stewart, ID (1987) Woodridge Pilot Project: September 1985 to September 1986. Evaluation, unpublished manuscript, Probation and Parole Service, Queensland.

Garvey, M, Perkins, J \& Bridgeman, RP (1986) An Assessment and Evaluation System for the Queensland Probation and Parole Service, unpublished manuscript, Probation and Parole Service, Queensland.

Gendreau, P (1995) What Works in Community Corrections: Promising Approaches in Reducing Criminal Behaviour, Speech given at Corrections Today, IarcA Research Conference, Washington, USA.

Hart, BJ (1997) Recidivism Prediction and Parole Decisions, available at <http://www.umn.edu/mincava/hart/recidiv.htm>.

Hayes, H \& Geerken, M (1997) 'The Idea of Selective Release', Justice Quarterly, vol 14, no 2, pp 353-370.

Hayner NS (1958) 'Why Do Parole Boards Lag in the Use of Prediction Scores', The Pacific Sociological Review, vol 1, no 2, pp 73-76.

Hoffman, PB \& Adelberg, S (1980) 'The Salient Factor Score: A Nontechnical Overview', Federal Probation, vol 44, pp 44-52.

Holland, TR, Holt, N, Levi, M, \& Beckett, GE (1983) 'Comparison and Combination of Clinical and Statistical Predictions of Recidivism Among Adult Offenders', Journal of Applied Psychology, vol 68, no 2, pp 203-211.

Jones, PR (1991) 'The Risk of Recidivism: Evaluating the Public Safety Implications of A Community Corrections Program', Journal of Criminal Justice, vol 19, pp 49-66.

Motiuk, LL (1993) 'Where are We in Our Ability to Assess Risk?', Forum on Corrections Research, vol 5, no 2. Available on-line at $<\mathrm{http} / /$ www.csc-scc.gc.ca/text/pblct/forum/ e052/e052f.shtml> 
Queensland Corrections (1996) Practices and Procedures Manual, Community Corrections Manual.

Queensland Corrective Services Commission (QCSC) (1996/97) Annual Report, State Government Printer, Queensland.

Roberts, JV (1993) 'Risk Management: the Views of the Public and the Challenge to Corrections', Forum on Corrections Research, vol 5, no 2. Available on-line at $<\mathrm{http}: / / \mathrm{www} . \mathrm{csc}-\mathrm{scc} . \mathrm{gc} . \mathrm{ca} / \mathrm{text} / \mathrm{pblct} /$ forum/e052/e052g.shtml $>$.

Schumacker, MA (1985) 'Implementation of A Client Classification and Case Management System: A Practitioner's View', Crime and Delinquency, vol 31, no 3, pp 445-455.

Serin, RC (1993) 'Decision Issues in Risk Management', Forum, Canada: On Corrections Research, vol 5, no 2, pp 22-25.

Sherman, L \& Smith, D (1992) 'Crime, Punishment, and Stake in Conformity: Legal and Informal Control of Domestic Violence', American Sociological Review, vol 57, no 5, pp 680-690.

Tallant, C \& Strachan, R (1995) 'The Importance of Framing: A Pragmatic Approach to Risk Management', Probation Journal, vol 42, no 4, pp 202-207.

Tripodi, T, Fellin, P \& Meyer, H (1969) The Assessment of Social Research, Peacock Publishers, Illinois.

Trotter, C (1995) The Supervision of Offenders - What Works? First and Second Reports to the Australian Criminology Research Council, Social Work Department, Monash University, Victoria.

Wilson, L (1997) Summary Findings related to Risk/Needs Inventory Study and Recommendations Arising, unpublished paper, Queensland Corrective Services Commission.

Winters, B (1999) An Examination Of The Predictive Validity Of The Queensland Community Corrections Risk Needs Inventory, unpublished MA(Hons) thesis, Griffith University, Brisbane, Queensland. 